\title{
Fantasy visions, informal urbanization, and local conflict: an evolutionary perspective on smart city governance in India
}

\author{
Debadutta Parida $\mathbb{D}$
}

Accepted: 24 September 2021 / Published online: 18 October 2021

(C) The Author(s), under exclusive licence to Springer Nature B.V. 2021

\begin{abstract}
Smart city imaginaries have emerged in southern cities driven by neoliberal logics in the urban space. Scholarly work in India has continued to engage with sweeping accounts of cities as opposed to detailed empirical studies of local projects. This paper attempts to address this gap through an in-depth ethnographic inquiry of a slum redevelopment project in the city of Bhubaneswar, India. The key objective is to understand the ways in which informal residents adapted to and changed smart city policies in India in recent years. Using an evolutionary lens, and drawing on participant observation; document analysis; and semi-structured interviews, the paper puts forth a descriptive cases that advances the notion that smart cities imaginaries have resulted in abrupt changes in the institutional context while getting entangled itself within the legal system. The paper also demonstrates how smart cities discourses counter-intuitively result in emergent spaces of resistance in the form of counter-hegemonic practices, thus allowing spaces for the evolution of new actors and imaginaries from unfamiliar territories. The paper concludes by discussing that city planning and governance pathways in India risk creating complicated path dependencies and
\end{abstract}

D. Parida $(\bowtie)$

School of Urban and Regional Planning, University of Alberta, 3-107A Tory (H.M.) Building, Saskatchewan Drive NW, Edmonton, AB, Canada

e-mail:dparida@ualberta.ca rigid governance future pathways that may amplify conflict.

Keywords Smart cities - Informality - EGT · Coevolution · Urban Governance · Indian cities

\section{Introduction}

Smart City initiatives are a dominant phenomenon in the urban context worldwide in the 21th century. In India, Smart cities have assumed a centralized role in building futures of cities in India, triggered by regime change in the year 2014. Scholars have previously critiqued the 100 Smart Cities Mission in India, terming it as a 'post-colonial utopian dream', driven by neoliberal logic and entrepreneurial interest in the city that has the potential to undermine democratic values (Chakrabarty, 2018; Chatterjee \& Kar, 2015; Das, 2020; Datta, 2015a, 2015b; Satpathy, 2021; Watson, 2015). The relevant textual and visual perspectives and representations of smart city imaginaries across geographies have been extensively studied, documented, and examined across disciplines (Chatterjee \& Kar, 2015; Hoelscher, 2016; Hollands, 2008; Kummitha \& Crutzen, 2017; Lindner \& Meissner, 2019; Prasad \& Alizadeh, 2020; Söderström et al., 2014). 
In India, the focus is largely on the technological interventions and psychological effects on public performance and performativity of smart technologies and services (Chatterjee \& Kar, 2015; Chatterjee et al., 2018a; Kushwaha et al., 2021; Reshmi, 2021). Scholars within social sciences have addressed significant critics of the smart city movement in cities, yet most social science literature largely engages with the phenomenon rhetorically with sweeping accounts of cities in the 100 Smart cities list (such as studies by Datta, (2015a) in Dholera, India). Datta, (2015a) acknowledges in her influential paper, that "the available tools of analysis... ...need to be complemented by ethnographic details on the everyday struggles faced by those at risk of being excluded from India's urban future." Christofi et al., (2021) contend that entrepreneurial shifts in city governance need more careful attention in urban studies. Following these leads, this paper focuses on addressing theoretical as well as a practical gaps in the context of smart cities. Theoretically, it seeks to advance the growing paradigm of evolutionary approaches to urban governance in planning and development literature which remain largely understudied in planning (Beunen et al., 2015). Practically, it seeks to add knowledge on smart cities through ethnographic accounts of grassroots-level projects and draw policy and planning implications from them. In particular, the key focus areas of this paper are the evolution of conflict in smart urban governance, and the ensuing negotiation of differences between citizens and the smart city institutional apparatus. Both these aspects remain unexplored in the Indian city context. In this paper, I seek to understand the impact of smart city imaginaries on the collective and political life of informal residents in cities. I use an evolutionary lens, and the main research question is how have the slum dwellers adapted and been changed by smart city projects in Indian cities?

In the study, I highlight the co-construction of actors, institutions, and imaginaries in the city space, thus making governance pathways dynamic. I argue that smart city imaginary has played an active role in rendering existing institutions and past visions inactive, while successfully replacing past imaginaries about planning and governance. In the process of doing so, the smart city imaginary has intensified conflict, resulting in a quick change in the institutional context under pressure, and embedded the legal system within urban development, making future pathways complicated.

In the rest of the paper, I elaborate on various aspects of the research. Section 2 presents a brief review of the literature on smart cities in India. Sections 3 and 4 describe the methodology and theoretical frames used in the study. This is followed by Sect. 5 wherein the case study and findings are presented. In Sect. 6, the key observations are discussed in the context of existing theory, followed by a brief description of the implications of the study. The concluding arguments are presented in Sect. 7 with broad recommendations for future pathways.

\section{Smart cities in India: a brief review of scholarly works}

\section{Background}

The Smart Cities Mission is a central government initiative in India, launched in the year 2015, triggered by a political regime change at the center. The Mission is reflective of a paradigm shift in India's planning and development policy response to increasing levels of urbanization (Pathak, 2020; Praharaj et al., 2018). The mission aims to make a hundred cities 'smart' by the year 2023. The cities were selected in five phases based on a state-level competitive application-based format that included the municipal performance of infrastructure services and utilities. The mission is broadly based on a combination of institutional structures and urban-design-based approaches in planning. There are four main components-Areabased retrofitting of particular city areas; urban renewal projects; affordable housing for the urban poor; and pan-city development projects that involve 'smart' technological interventions.

\section{Key drivers of smart cities projects in India}

Smart City Mission is materializing in many Indian cities in the form of projects, handled by different existing state departments. Drivers of smart city projects are globalization, technological advances in urban spaces, increasing investments in the marketing field, and entrepreneurial shifts in governance that have resulted in attempts to city branding (Christofi et al., 2021). Local drivers are under institutional 
pressure to involve the private sector due to increasing pressures of urbanization, political influence, and environmental risks (Alsaid, ).

Smart governance: proponents and critics

A brief review of literature on smart city governance reveals that scholars remain divided across disciplinary lines both in terms of focus, lines of inquiry as well as their observation on the usefulness of smart cities in Indian cities. The proponents of smart cities are focused on bridging the existing gaps between policy and practice, exploring ways to achieve a digital turn in Indian cities. Critical standpoints, on the other hand, are mostly from the social sciences, with the key line of argument being that cities need to be looked at from multi-disciplinary angles rather than the present discourse of reducing complexity through technological interventions.

In the area of smart governance, literature by key proponents can be understood in three approaches of study: overall approaches (city-wide), particular strategies (varied scale), and tactics and techniques (more local forms of interventions). City-scaled approaches to smart governance range vary across disciplines. (Chatterjee \& Kar, 2015) propose three main principles that smart governance can lean oncoalescence, practicality, and involvement. They suggest increased citizen awareness and policy integration as two key determinants of good smart city governance. This is complemented by Jnr and et al., (2021) who suggest service integration as a key approach to smart governance. (Kar et al., 2019) on the other hand, explore the possibility of 'smart nations' by increasing the smart governance principles across regions encompassing rural areas in India. Khatibi et al., (2021) propose merging of twin approaches of 'smart' and 'resilience' to form smart-resilient governance in cities.

Key strategies to achieve the above approaches have been explored by scholars, ranging from strategic visualization through cognitive mapping (Vaz et al., 2021); increasing awareness of citizens through educations campaigns to gain public trust in the smart governance pathway (Chatterjee, 2020; Chatterjee \& Kar, 2017; Chatterjee et al., 2017, 2018a, 2018b, 2018c); human-oriented planning with increased public participation (Feng, 2019); focus on ethical and legal awareness regarding privacy and cybercrimes (Chatterjee et al., 2018a, 2018b, 2018c; Vaz et al., 2021) and datadriven decisions and support system (Kar et al., 2019; Kushwaha et al., 2021).

Other scholars have focused on more local tactics to achieve smartness in cities, largely driven by datadriven technologies and digital urbanism. Chatterjee and Kar, (2015) contend that smart cities will need smart technology or ICT (Information and Communication Technology), while acknowledging that the present realities of Indian cities pose important challenges in achieving this, namely in the form of lack of awareness among public and lack of technical skills. Chatterjee et al., (2018a, 2018b, 2018c a \& b) contend that training in information technology and IoT-related awareness can help in addressing the above challenge. Reshmi, (2021) advanced this idea by suggesting that technology adoption in Indian cities will be determined by psychological factors such as perceived usefulness of the 'smart' services as well as ease of use for the public. In general, it is observed that most scholars agree that a digital or smart turn in Indian cities is evident, and needs to be backed with technology-driven interventions in governance pathways.

\section{Critiques of smart cities mission}

Hoelscher (2016) studied the evolving national discourses in India, suggesting that despite the increase in clarity over the conceptualization of the concept and approaches towards policy integration, the chances of success remain uncertain. Prasad and Alizadeh (2020) advanced the discourse claiming that citizen and infrastructure dimensions have taken center stage in smart city policymaking. Kitchin (2015) and Parida (2020) contend that smart cities are state-centric and market-driven, and are actively promoting an authoritarian state in the near and long term. In a compelling article, Mattern (2017) dismisses the 'city as computer' paradigm suggesting that cities need to be seen beyond performance measurement indicators to understand everyday relationships between people, institutions, and other well-being. Similarly, Cardullo and Kitchin (2019) in their study contend that smart cities are less people-oriented, which is a result of their creation and imagination without local knowledge and realities. Recent experiences in India highlight that smart cities in India are a post-colonial utopian dream 
that advances the interests of the rising urban middle class (Datta, 2015a, 2018; Watson, 2015). Other issues related to smart governance in Indian cities are ambiguity in its conceptualization (Praharaj et al., 2018); too much focus on technological aspects of the city while ignoring long term vision (Harris, 2015; Parida, 2020; Prasad \& Alizadeh, 2020); and inadequate attention on policy integration matters (Praharaj et al., 2018). In totality, most studies highlight that further empirical work needs to be carried out to support these analytical works on smart cities in the Indian context.

\section{Data and methods}

\section{Research setting}

I employ a qualitative methodological framework in this paper based on the case study method (Flyvbjerg, 2006; Ruddin, 2006; Yin, 2009, 2012). I extensively align towards a combination of interpretist and 'evolutionist' lens towards the issue studied. The key message is that any planning and development action is based on a particular context, and key decisions by actors are always based on particular perspectives. The context and perspective, in return, are influenced by past actions and future imaginations (for example past plans, policies and decisions, and future visions), and hence are always dynamic and constantly evolving.

\section{Data collection and analysis}

I draw on ethnographic fieldwork in Bhubaneswar city in India drawing upon participant observation; document analysis; and semi-structured interviews of slum residents, professional city planners, activists, elected political leaders, municipal officials and urban planners, academic experts, and local non-governmental organizations. The unit of analysis for the study is a slum redevelopment project as part of the Smart City Proposal in Bhubaneswar. The key documents analyzed were media articles relevant to Smart Cityrelated actions in Bhubaneswar city, case laws related to legal conflict between slum residents and the state, and Smart City proposal-related documents of the city. In total, I conducted 22 semi-structured interviews of key actors relevant to the case between June 2019 and August 2021. The interview questions were based on various actors' perspectives and interpretations of the Smart city project; how its materialization is or changing the socio-political life of the slum dwellers. Owing to the ongoing restrictions around the Covid-19 pandemic, eleven out of fourteen in the first phase were conducted through phone conversations and online platforms. The second phase involved inperson interviews (eight in number) with the actors. The identities of all interviewees were kept confidential, by storing them safely, as well as by encrypting their original names.

All interviews were transcribed and coded using the NVIVO software. Most interviews lasted between 45 and $75 \mathrm{~min}$ on average. After transcription, the relevant identified narratives were coded using descriptive and thematic codes. The key themes were identified concerning the research question at hand as well as the evolutionary theoretical lens appliedurban everyday politics, mutual relations (between slum dwellers and state), planning process, mutual demands, strategies, the immediacy of issues, and framing of narratives. The themes were specified into sub-categories based on the content analyzed. For example, the theme framing of narratives was further specified as 'livelihood and economy, 'risk and vulnerability, 'socio-cultural, 'insecurity', and 'social and legal justice'. Similarly, the theme 'mutual strategies' was further categorized as 'legal', 'territorial', 'attitudinal', and 'institutional'. Following the coding, the codes were arranged longitudinally (from past to present, based on the narratives in the interviews) to get a better understanding of the evolution of codes (how codes closer to the present build upon those in the past) concerning time. This approach is useful to understand present-day issues concerning past events that often find themselves implicitly in present narratives.

\section{Theoretical framework}

Two theoretical frames guide the research work, which is discussed in this section. First, the role of urban imaginaries as an emerging scholarly focus in planning and governance is discussed. This is followed by introducing the theoretical framework of the study-Evolutionary Governance Theory (EGT). EGT is a post-structuralist approach to planning and governance; a flexible combination of Luhmann's 
Social Systems Theory and institutional theories (Luhmann, 1995).

Role of imaginaries in urban governance

Urban spaces are constituted by an open interplay of imaginations, discourses, and material spaces (Lindner \& Meissner, 2019). They play a key role in the constant deconstruction and reconstruction of this interplay. Planning and governance can be studied as institutional frameworks that take into account history, cultures (institutional and forms of governance for example), past and future imaginaries, and desires (fantasies). Going beyond the materiality of space, imaginaries play a rather implicit part of every day (imagined and experienced) life in the urban (Çinar \& Bender, 2007). They range from visions of the future based on fantasies of individuals and communities (smart cities, eco-cities, sustainable cities, resilient cities, and so forth); to performative activism in the streets motivated by justice. Imaginaries are conceptualized, experienced, and performed simultaneously_and are a significant point of inquiry for planning and governance scholars (Dunn, 2019; Laurian \& Inch, 2019; Lindner \& Meissner, 2019).

The role of imaginaries has been extensively studied ever since social theory took a spatial turn (largely driven by exploration by scholars such as Henri Lefevbre, Michel Foucault, David Harvey, Doreen Massey, Edward Soja). Recent scholarship of relevance for this paper has focused on the intersections between urban imaginaries in practice with politics. Potter, (2020) presented the key links between urban imaginaries in practice with the "neoliberal logics" of space. Similarly, Caprotti (2019) and Adama (2017) explored the role of smart imaginaries across geographies, both in the northern and southern context in advancing new and emergent forms of elite power. In general, scholars contend that contemporary urban imaginaries driven by entrepreneurial city logics of space in emerging cities seem to be reinforcing exclusion, with the complicity of urban planning tools (Potter, 2020).

Evolutionary approaches to understand

Governance pathways

Evolutionary Governance Theory (EGT) by Beunen et al. (2015) provides a theoretical lens to understand the governance process from an evolutionary perspective. EGT considers coevolution as the central idea-a system is characterized by an ongoing system of change, in which existing structures are constantly at interplay, changing and shaping each other. Coevolution relies on the idea of iteration and recursive process, where several things co-evolve simultaneously or in different sequences, and result in new system configurations. In a system of governance, EGT assumes a complex interplay between actors and institutions $(\mathrm{a} / \mathrm{i})$; power and knowledge $(\mathrm{p} / \mathrm{k})$; and discourses within a wider context of formal and informal (f/inf) institutional and pathways (that are influenced by path and goal dependencies).

Actors here refer to individuals, groups, or organizations involved in the planning and governance process. Institutions are the planning and governance tools that make governance and planning possible (such as master plans, policies, regulations). Institutions are created when actors interact and coordinate with each other. Actors and institutions interact and coordinate within a complex system of discourses, that are constantly shaping and being shaped by each other. Institutions can be formal and informal, and a strict distinction is problematic from an EGT angle. Formal institutions (and associated actors) have legitimacy at a particular time, while others are in the margins and are 'temporarily' informal, till some systemic change can result in formal and informal institutions swapping spaces within the system. System here refers to functional systems such as governance systems, planning systems, the legal system, systems of democracy that exist through communication, and functional differentiation within a social system in the Luhmann-ian sense (Assche et al., 2017; Djanibekov \& Valentinov, 2015; Luhmann, 2004).

Planning systems thus can be imagined as complex, involving constant interaction, collisions, struggle, coalitions as well as temporal combinations, reconfigurations, and transformation between imaginaries, discourses, and the resulting materializations of projects that are born out of these interactions. These complex interactions create new forms of power dynamics, flexibilities, and rigidities in the governance pathways, which are often difficult to change swiftly, which are known as path dependencies. Power dynamics and path dependencies influence which actors, institutions, and discourses are included or excluded in planning strategies. 
Many studies have used EGT to understand governance processes and structures within particular contexts, studying why particular planning approaches are successful in certain (and unsuccessful in other), what theories they implicitly assume and obscure, and to what extent various elements ( $\mathrm{a} / \mathrm{I} ; \mathrm{p} / \mathrm{k}$ and $\mathrm{f} / \mathrm{inf})$ are contingent (Assche et al., 2015; Djanibekov \& Valentinov, 2015; Schlüter et al., 2020; Vries \& Aalvanger, 2015). In this study, EGT is used since it is flexible and compatible with the use of multiple approaches, theories, and concepts across disciplines.

\section{The Shantipally basti redevelopment case:Key findings}

\section{Background}

The Shantipally 'basti' (local word for slum) is located in Bhubaneswar city in Odisha state in India. Bhubaneswar city was the first in the top twenty cities that were selected in the Smart City Mission in India, launched by the central government in the year 2015 . The city had a population of 0.84 million in 2011, with a decadal growth of 27.74 percent, which makes it one of the fastest-growing cities in India. The city has nearly 0.16 million residents (close to one-fifth population) residing in slums (Anand \& Deb, 2017). As part of its Smart City Proposal in 2015, Bhubaneswar city proposed city-wide (intelligent transit systems, parking management, emergency management, and other technology-driven interventions to city utilities and services) and local-scaled interventions (or area-based development). These interventions were aimed at making large-scale territorial changes to the urban areas within the city, to make 'smart' neighborhoods in a city aspiring to be world-class. The main aspect of the smart city proposal was the area-based development project known as BTCD (Bhubaneswar Town Centre District), spread over nearly 3 square $\mathrm{km}$. of land. The location for BTCD was selected by citizens through online polls. The BTCD comprises multiple projects, mostly infrastructural inspired by ideas related to transit-oriented development, such as street improvements through urban design interventions, parks, housing, slum redevelopment, and social infrastructure.
Emergence of conflict

A key part of the BTCD is the 'Shanti Nagar Awas Yojana' or locally called the Shantipally Basti Redevelopment Project, in which nearly 2232 dwellings are proposed in an area of 10 acres. The location of this redevelopment project is near Shantipally basti, which has been existing in the city for more than three decades. The population in the basti drastically increased in the past decade, largely driven by an active state policy that is focused on developing the city as the main economic center in the state.

Since the year 2015, the BTCD was projected as the future identity of the city by officials, thus advancing ideas that the slum redevelopment is necessary to go forward with the creation of smart city neighborhoods. By the end of 2017, the Bhubaneswar Municipal Corporation (BMC) had invited applications from private developers to execute the project. In November and December 2017, two key meetings took place between the local elected authorities (mayor and other politicians representing the government), to create 'awareness' among the slum dwellers regarding the redevelopment project. In these meetings and many more informal ones that followed up, the slum dwellers were assured by the local authorities that they will be temporarily shifted to transit houses, while their existing houses would be demolished. Eventually, they will receive homeownership of the multistoried housing built exclusively for them.

Interestingly, around this time, in other parts of the city, the local planning agency or the Bhubaneswar Development Authority (BDA) was involved in many forced evictions of other slums. The city was hosting the Hockey World Cup in 2018, and as part of the beautification exercise before the games, decided to clear out many slums and put them in transit homes far away from the games area. This resulted in a lack of trust among many residents of Shantipally Basti, who feared losing their existing housing and livelihood, just like the other slum residents. The initial voices resented the approach of the state. One resident described:

We want the government to give us proper documents and not just verbal assurances. Most of all, we need land, not these small ones, but at least 400 square feet. Also, we need it near our workplace. They tell us that they want to give us 
land in Chandaka (a forest land on the outskirts of the city). How will we survive there? No, we will not go there.

\section{Persistence of conflict}

By the year 2018, many activists and the media had taken interest in the project and the emerging unrest among slum dwellers against the new smart citydriven project, that directly put them at immediate risk. 'Shantipally basti' comprises nearly 1200 households that are closest to the ongoing redevelopment project, of which 200 houses are at immediate risk of eviction due to the redevelopment project. A fraction of the households within the slum decided to take help from the activists and decided to protest against the project and negotiate better terms. Their key demand was that they be given land ownership as opposed to a home or apartment ownership that was offered to them. This resulted in further disagreements between the slum dwellers themselves, with some households ready to accept the proposal, some others actively refusing it, and some others choosing to remain neutral.

The conflict was further exacerbated by the involvement of local politicians of the ruling party, who convinced the group which agreed to the proposal, while also managing to convince more households. This was alleged by one of the activists, to have been carried out by active coercion:

Slum dwellers are forced to support the ruling party; else they are targeted by evictions. Slumdwellers have their insecurities-financial, physical; at the heart of their insecurity is lack of tenured land.

The involvement of political parties and various activists has complicated things, resulting in fragmented groups within the basti, which then led to multiple narratives based on allegiance and socialidentity of each group (either opposers, supporters, or neutral wait and watch approachers). One resident who was part of the group that opposed the project said:

In Shantipally basti, there are 1200 housescontaining supporters of BJD (ruling party), $B J P$, Congress, CPI (opposition parties), I, and another activist (name withheld). BJD households want to take an apartment given by the government and have agreed to be displaced, BJP supporting households are in complete opposition to the redevelopment project. Our position is that we need land in the same location and not flats (apartment). This has led to internal conflicts between people.

The events unfolding between 2018 and 2019 led to two diverging interpretations of the smart city project. The key opposition group within the slum that comprised of nearly 200 households, with active support by the BJP (the main opposition party) as well as many activists continued their protests against the project. In their view, the project was a direct threat to their livelihood and social network. They used their political network as key support for their narratives.

On the other hand, the municipal authorities and planners see the slum dwellers and informal urbanization in the city as the main cause and creator of problems in the city. They saw informal developments as the main barrier to any effective urban development. One interviewee said:

The fact that we are stuck in informality is one of the big problems. We allow those people to stay there thinking where will they go. We forget that the law is same for everyone. I know they have nowhere to go, but still they are sitting there illegally. If you take hard legal action, then humanitarian organizations will come and be sitting and doing dharnas (protests), that you cannot evict those people.

This highlights changing approach of the municipal authorities towards the slum dwellers. The discursive shift is easily seen here-from slums being framed as unwanted spaces that needed to be 'regularized' and brought within the Smart neighborhood; to slums being illegal, barriers to the Smart City project, thus affecting the image of the city.

Over the next many months, the two groups (opposing slum dwellers and municipal government) continued to disagree over the project, which eventually resulted in a communication breakdown between them. The lack of communication (between groups within the slum; as well as between the opposing group and the state) became the norm, while the communication intensified with the supporting groups within the slum. This coincided with the municipal 
government actively execute the project, putting many houses at acute risk of evictions within months, without any adequate arrangement for transit accommodation.

\section{Evolving strategies}

Due to the rapid escalation of risk, the residents decided to mobilize and adopt multiple strategies to either delay or oppose the project. In early 2019, few grassroots activists within the 200 households in the opposing group, who emerged due to support from the mainstream activists decided to approach for legal help in the Orissa High Court to obtain a stay order of their eviction due to the project. Additionally, they also filed an RTI (Right to Information) document, asking for further details of the process of allocation of apartments. They successfully managed to get a stayorder from the court which is valid as of this date. When discussing the various strategies for self-organization and anti-eviction, and activist noted:

We use a range of actions to deal with evictions. We mostly take help of RTI (Right to Information), court appeals, demonstration while other times also engage with direct dialogue with the $M L A$ and MP (politicians).

Conversely, the state also resorts to various strategies to fulfill its visions for the future. For example, in January 2020, the state government directed all district officials to "take urgent steps for eviction of encroachments, particularly high-value urban and semi-urban lands, lands allocated to educational, health and other institutions, water bodies, rivers, rivulets, drains and public roads on priority and furnish monthly reports. Action plan in purpose must be drawn in advance and executed for eviction purposes" (Govt. of Odisha, 2020). This highlights shifting approaches by the state action to deal with slum dwellers-from explicit violent eviction drives in the previous years, towards subtler strategies such as the use of legal tools. These tools were combined with passive-aggressive actions. For example, in the aftermath of cyclone Fani in June 2019, many slum dwellers in Shantipally Basti were affected, yet there were accusations of discrimination in relief allocation at the local level. Further, in late 2020, the municipal authorities installed water meters in households in Shantipally Basti, and informed them that they will need to pay for water soon; all while adequate municipal supply being absent in many parts of the slum. The tensions between the groups are ongoing, with no real possibility of a peaceful agreement or a shared collective vision of the project as well as the future of the residents.

Key observations from the case

\section{Discursive creation of 'smart neighborhoods' as a desired object of imagination}

The observations made in the case reaffirms the discourse that the Smart City initiative is a direct result of hegemonic middle-class discourses in tandem with neoliberal calls for an entrepreneurial city that is based on an urban imaginary that is oriented towards urban spaces in cities in the global north. The Smart City initiative in Indian cities, when conceptualized and problematized from this perspective, no longer remains just a politically neutral 'social construct' but rather an active neoliberal project. The 'smart' imaginary also assumes implicitly that smart neighborhoods are superior. They create a demand for 'Smart' governance frameworks that easily privilege the urban middle class, real-estate developers, and the social elite while marginalizing the slum dwellers further by questioning their legal citizenship and legitimacy while using local scaled law enforcement and structural violence (see similar findings by Das, 2020; and Datta, 2015b).

\section{Augmented marginalization of informal settlements}

The process of materialization of the 'smart' neighborhood formation in Bhubaneswar city is resulting in the forced displacement and conflict within the city space between the slum dwellers and the state. This contributes to the increasing vulnerability and marginalization of the slum dwellers who find themselves far away from the new imaginary. On the ground, many slum dwellers and slum activities highlighted how the forced displacement is negatively affecting their socio-political networks and legitimacy in the city. In this context, the smart imaginaries are in direct conflict with the existing informal nature of urbanization that dominates the material landscape. 


\section{Counter-conducts and the struggle for legitimacy}

Almost counter-intuitively, one of the key observations was that smart cities initiatives are resulting in a gradual emergence of insurgent practices (in the form of counter-hegemonic practices) to counter the elitedriven smart imaginary in Bhubaneswar city, often from unfamiliar territories. The affected slum dwellers balance their actions by holding on to political linkages to attain 'formal' citizenship status in the city while engaging actively in counter-hegemonic practices against the smart city discourse. The counterhegemonic strategies are short-term in nature, focused on immediate survival needs as well as delaying the inevitable. These actions are further balanced by longterm actions based on the slum dwellers' desire to achieve formality first, to achieve legitimacy in the urban space later-an alternate imaginary based on livelihood needs and political expediencies.

\section{Discussion}

Co-construction of actors, institutions, and imaginaries in governance

The Shantipally case studied in this paper shows that imaginaries play a key role in shaping local governance pathways. Studying the case from an evolutionary perspective allowed us to understand how these changes enabled the construction and reconstruction of imaginaries. The case showed how the active construction of smart imaginaries influenced largescale territorial changes, changed institutional context, and the emergence of new actors (for similar observations, see Alsaid, 2021b; Christofi et al., 2021; Datta, 2015b). The smart imaginary has created new rules and resulted in changes in land use. The emphasis by the state to create new and smart neighborhoods in combination with the involvement of new actors (slum leaders, activists, private developers, and local politicians) changed the institutional context-in the form of new plans, policies, rules, and legal frameworks that achieved formal status, rendering earlier masterplans and previous schemes rather dormant.

Datta (2015a) following Watson (2015) contended that smart cities would increase attention and skew budgets away from the urgent basic needs of the poor while channeling the same towards corporate demands. This case highlights that while this is partially true, yet the smart imaginaries have also actively contributed towards normalizing conflict and mistrust between slum residents and the state. The new projects, gradual evolution, and persistence of conflict create lower possibilities of participatory forms of governance any time soon.

The Shantipally case is a very dynamic example of how actors, institutions, and imaginaries are constantly changing. Institutional context assumed importance here since it allows significant changes in the imaginaries, narratives around the past and the future alike, as well as actors at the local level. The smart imaginary of the state aimed at territorial shifts (by providing homeownership to the slum dwellers) but eventually evolved into a discursive shift around slums (from 'slums are illegal, yet part of inclusive governance' towards 'slums are barriers to the smart city mission, affecting the image of the city'). The new institutional context formed in this process brought new actors, while also delegitimizing old actors and institutions (old plans and policies replaced by new ones, while reliance on political patronage shifted towards reliance on the legal pathways). New groups such as activists and slum leaders became important actors, getting space in the formal governance decisions, while old ones such as local politicians worked mostly through informal channels, becoming inactive gradually. Thus, strategies of actors (in this case the state actors), working within a constantly changing institutional environment created and changed other actors (activists).

Contextually, alternate imaginaries were used by slum dwellers informally to challenge and delegitimize the existing planning system, through the emergence of new narratives around the future of the city (such as 'the state is the bad guy'). The legal system gradually became embedded with the planning system, which increased codification significantly. Following Djanibekov and Valentinov (2015) this study advances the idea that increased rules (including past laws that can be applied in the interpretation of present issues) around governance help reduce complexity in cities. Law limited the ability of the planning system by codifying it further. The legal route was used to interfere and simplify the planning system to reduce conflict. In the long term, however, past laws can increase rigidity by reducing the chance of co- 
construction of imaginaries, thus undermining the planning system.

Implications of the study

The study has several implications for urban theory and practice. Theoretically, the study provides a useful lens using EGT as a descriptive tool to understand the governance processes in the past and future in the southern context. Using an evolutionary lens, the study highlights how state actors deliberately and in-deliberately exploit functional differentiation (in this case, between planning and law) and control society using informal structures along with formal rules. It also advances the idea that fantasies, imaginaries based on ideologies, and political and economic structures in cities play a key role in evolution or governance shifts in time. Methodologically, the study adds an important empirical case to the existing body of knowledge on smart governance in the southern context through a post-structural and critical evolutionist lens.

Practically, the study has a few insights for policymakers and planners in southern cities. Firstly, the study advances the evolving idea that formal/ informal distinction in cities is not useful. Since the institutional configuration is dynamic, actors are constantly self-organizing, adapting, and changing their roles with time (from formal to informal and vice versa). Secondly, the case highlighted in this paper showed how the embedding of law into planning can reduce conflict in the short term, however, in the long term it undermines (makes it powerless) any meaningful planning since it creates rigid path dependencies (old legal judgments can stop new visions). In this context, any new projects for the future should take cues from past experiences and avoid potential legal conflicts during the masterplan stage by adopting a combination of deliberation with residents at risk from the planning projects. Furthermore, from a policy point of view, planning institutions can benefit from acknowledging the role of increased informal power and networks, instead of adopting rigid frameworks that remain from the past.

\section{Concluding thoughts}

Using the concept of co-evolution, this study investigated various challenges and adaptations made in evolving smart governance pathways in southern cities. The study revealed that gradually evolving imaginaries (sustainable, world-class to the digital and smart city) are changing the existing institutional configuration significantly. In doing so, they are causing short-term couplings between planning and law, with possibilities of rigid frameworks and lockins in the future.

The study has also highlighted how past actorinstitutional configurations and power-knowledge frameworks (in this case, middle-class elite frameworks) have resulted in present imaginaries and city identities, and are actively shaping territorial space as well as creating discursive objects (and subjects). This investigation has the potential to explore new aspects of this co-evolution, by providing nuanced perspectives on the role of urban imaginaries in shaping planning. The key here is to understand imaginaries as inherently unstable, their associated actor-institutional configuration as constantly changing, and something that can change quickly under pressure from other systems such as legal or political systems.

Further work can focus on the role of imaginaries in planning from different lenses, such as the Lacanian lens (following Gunder, 2015); or to identify more precisely the nature and kind of territorial changes occurring due to the smart city visions in cities, what actor-institutional and power-knowledge configurations are enabling what extent of inclusion in possibilities of a shared vision for a 'smart' future in cities in the southern context.

Funding No funding was acquired for the study.

\section{Declarations}

Conflict of interest The author declares no conflict of interest.

Data availability The data used in the study is mostly drawn from semi-structured interviews. It is confidential, yet some aspects of coding and analysis can be provided if requested.

Ethical approval All ethical guidelines were followed in line with the University of Alberta's REB.

Consent to participants All participants in the study provided their consent to participate, and be allowed to be interviewed, as well as their words to be used in this article in quotes. 


\section{References}

Adama, O. (2017). Urban imaginaries: Funding mega infrastructure projects in Lagos, Nigeria. Geo Journal, 83, 257-274. https://doi.org/10.1007/s10708-016-9761-8

Alsaid, L. A. Z. A. (2021a). Performance measurement in smart city governance: A case study of an Egyptian city council. Journal of Accounting in Emerging Economics, 11(3), 395-430. https://doi.org/10.1108/JAEE-09-2020-0244

Alsaid, L. A. Z. A. (2021b). Smart city dynamics and multi-level management accounting: Unfolding a case of sustainable enterprise resource planning. Sustainable Accounting, Management and Policy Journal. https://doi.org/10.1108/ SAMPJ-08-2020-0283

Anand, G., \& Deb, A. (2017). Planning "Violations", and urban inclusion: A study of Bhubaneswar. New Delhi: IIHS.

Van Assche, K., Beunen, R., \& Duineveld, M. (2013). Formal/ informal dialectics and the self- transformation of spatial planning systems. Administration \& Society. https://doi. org/10.1177/0095399712469194

Assche, K. V., Beunen, R., \& Duineveld, M. (2015). An overview of EGT's main concepts. In R. Beunen, K. Van Assche, \& M. Duineveld (Eds.), Evolutionary governance theory: theory and applications. Springer.

Assche, K. V., Beunen, R., \& Duineveld, M. (2017). Co-evolutionary planning theory evolutionary governance theory and its relatives. In M. Gunder, A. Madanipour, \& V. Watson (Eds.), The Routledge handbook of planning theory (pp. 221-233). Routledge.

Beunen, R., Van Assche, K., \& Duineveld, M. (Eds.). (2015). Evolutionary governance theory. Springer. https://doi.org/ 10.1007/978-3-319-12274-8

Burte, H. (2014). What's so smart about smart cities. Economic \& Political Weekly, 49(46). Retrieved from https://www. epw.in/journal/2014/46/commentary/smart-city-card.html

Caprotti, F. (2019). Spaces of visibility in the smart city: Flagship urban spaces and the smart urban imaginary. Urban Studies, 56(12), 2465-2479. https://doi.org/10.1177/ 0042098018798597

Cardullo, P., \& Kitchin, R. (2019). Being a "citizen in the smart city: Up and down the scaffold of smart citizen participation in Dublin Ireland. GeoJournal, 84(1), 1-13.

Chakrabarty, A. (2018). Smart mischief: An attempt to demystify the smart cities craze in India. Environment \& Urbanization, 31(1), 193-208. https://doi.org/10.1177/ 0956247818769234

Chatterjee, S. (2020). The safety of IoT-enabled systems in smart cities of India: Do ethics matter? International Journal of Ethics and Systems, 36(4), 601-618. https://doi. org/10.1108/IJOES-05-2019-0085

Chatterjee, S., \& Kar, A. K. (2015). Smart cities in developing economies: A literature review and policy insights. In IEEE Conference (pp. 2335-2340).

Chatterjee, S., \& Kar, A. K. (2017). Effects of successful adoption of information technology-enabled services in proposed smart cities of India. Journal of Science and Technology Policy Management, 9(2), 189-209. https:// doi.org/10.1108/JSTPM-03-2017-0008

Chatterjee, S., Kar, A. K., Dwivedi, Y. K., \& Kizgin, H. (2018a). Prevention of cybercrimes in smart cities of India: From a citizen's perspective. Information Technology \& People, 32(5), 1153-1183. https://doi.org/10.1108/ITP-05-20180251

Chatterjee, S., Kar, A. K., \& Gupta, M. (2017). Critical success factors to establish $5 \mathrm{G}$ network in smart cities: Inputs for security and privacy. Journal of Global Information Management, 25(2), 15-37. https://doi.org/10.4018/JGIM. 2017040102

Chatterjee, S., Kar, A. K., \& Gupta, M. P. (2018b). Alignment of IT authority and citizens of proposed smart cities in India: System security and privacy perspective. Global Journal of Flexible Systems Management, 19(1), 95-107. https://doi. org/10.1007/s40171-017-0173-5

Chatterjee, S., Kar, A. K., \& Gupta, M. P. (2018c). The success of IoT in smart cities of India: An empirical analysis. Government Information Quarterly, 35(3), 349-361. https://doi.org/10.1016/j.giq.2018.05.002

Christofi, M., Iaia, L., Marchesani, F., \& Masciarelli, F. (2021). Marketing innovation and internationalization in smart city development: A systematic review, framework and research agenda. International Marketing Review. https:// doi.org/10.1108/IMR-01-2021-0027

Çinar, A., \& Bender, T. (2007). Urban imaginaries: Locating the modern city. University of Minnesota Press.

Das, D. (2020). In pursuit of being smart? A critical analysis of India's s smart cities endeavor. Urban Geography, 41(1), 55-78. https://doi.org/10.1080/02723638.2019.1646049

Datta, A. (2015a). A 100 smart cities, a 100 utopias. Dialogues in Human Geography, 5(1), 49-53. https://doi.org/10. $1177 / 2043820614565750$

Datta, A. (2015b). New urban utopias of postcolonial India: ‘ Entrepreneurial urbanization ' in Dholera smart city, Gujarat. Dialogues in Human Geography, 5(1), 3-22. https://doi.org/10.1177/2043820614565748

Datta, A. (2018). The digital turn in postcolonial urbanism: Smart citizenship in the making of India's s 100 smart cities. Transactions of the Institute of British Geographers, 43, 405-419. https://doi.org/10.1111/tran.12225

Djanibekov, N., \& Valentinov, V. (2015). Evolutionary Governance, sustainability, and systems theory: The case of central Asia. In R. Beunen, K. Van Assche, \& M. Duineveld (Eds.), Evolutionary Governance theory: Theory and applications. Springer.

Dunn, N. (2019). Urban imaginaries and the palimpsest of the future. In M. Meissner \& C. Lindner (Eds.), The Routledge companion to urban imaginaries (pp. 375-386). Routledge.

Feng, M. (2019). Human-oriented smart city planning and management based on time-space behavior. Open House International, 44(3), 80-83.

Flyvbjerg, B. (1998). Rationality and power. University of Chicago Press.

Flyvbjerg, B. (2006). Five misunderstandings about case-study research. Qualitative Inquiry, 12(2), 219-245. https://doi. org/10.1177/1077800405284363

Flyvbjerg, B., \& Richardson, T. (2005). Planning and Foucault: In search of the dark side of planning theory. In P. Allmendinger \& M. Tewdwr-Jones (Eds.), Planning futures: New directions for planning theory.

Govt. of Odisha. (2020). Revenue and disaster management department notice for "eviction of unauthorized 
encroachments"; Notice No. RDM-LRGEB-MISC0010-2019/R7DM-2328 dated 13 January 2020.

Gunder, M. (2015). The role of fantasy in public policy formation. In R. Beunen, K. Van Assche, \& M. Duineveld (Eds.), Evolutionary governance theory. Springer.

Harris, A. (2015). Smart ventures in Modi's urban India. Dialogues in Human Geography, 5(1), 23-26. https://doi.org/ $10.1177 / 2043820614565865$

Hoelscher, K. (2016). The evolution of the smart cities agenda in India. International Area Studies Review, 19(1), 28-44. https://doi.org/10.1177/2233865916632089

Hollands, R. G. (2008). Will the real smart city please stand up? City, 12(3), 303-320. https://doi.org/10.1080/ 13604810802479126

Jnr, B. A., Petersen, S. A., Helfert, M., Ahlers, D., \& Krogstie, J. (2021). Modeling pervasive platforms and digital services for smart urban transformation using an enterprise architecture framework. Information Technology \& People, 34(4), 1285-1312. https://doi.org/10.1108/ITP-07-20200511

Kar, A. K., Ilavarasan, V., Gupta, M. P., Janssen, M., \& Kothari, R. (2019). Moving beyond smart cities: Digital nations for social innovation \& sustainability. Information Systems Frontiers, 21, 495-501.

Khatibi, H., Wilkinson, S., Baghersad, M., Dianat, H., Ramli, H., Suhatril, M., ... Ghaedi, K. (2021). The resilient - smart city development: a literature review and novel frameworks exploration frameworks. Built Environment Project and Asset Management. https://doi.org/10.1108/BEPAM03-2020-0049

Kitchin, R. (2015). Making sense of smart cities: Addressing present shortcomings. Cambridge Journal of Regions, Economy, and Society, 8(1), 131-136.

Kummitha, R. K. R., \& Crutzen, N. (2017). How do we understand smart cities? An evolutionary perspective. $\mathrm{Ci}$ ties, 67(March), 43-52. https://doi.org/10.1016/j.cities. 2017.04.010

Kushwaha, A. K., Kar, A. K., \& Dwivedi, Y. K. (2021). Applications of big data in emerging management disciplines: A literature review using text mining. International Journal of Information Management Data Insights, 1(2), 100017. https://doi.org/10.1016/j.jjimei.2021.100017

Laurian, L., \& Inch, A. (2019). On-time and planning: opening futures by cultivating a "sense of now." Journal of Planning Literature, 34(3), 267-285. https://doi.org/10.1177/ 0885412218817775

Lindner, C., \& Meissner, M. (2019). Introduction: Urban imaginaries in theory and practice. In C. Lindner \& $\mathrm{M}$. Meissner (Eds.), The Routledge companion to urban imaginaries (pp. 1-22). Routledge.

Luhmann, N. (1995). Social systems. Stanford University Press.

Luhmann, N. (2004). Law as a social system. Oxford University Press.

Mattern, S. (2017). A city is not a computer. Places Journal. Retrieved from https://placesjournal.org/article/a-city-isnot-a-computer/

Parida, D. (2020). God is in the market: Is city planning in India getting hijacked by free-market overtures?. Urban Voices. Retrieved from https://urbanvoices.in/city-planning-infree-market/
Pathak, C. R. (2020). Challenges of smart cities in India. In S. Bandyopadhyay, C. R. Pathak, \& T. P. Dentinho (Eds.), Urbanization and regional sustainability in south Asia (pp. 261-270). Springer.

Potter, E. (2020). Contesting imaginaries in the Australian city: Urban planning, public storytelling and the implications for climate change. Urban Studies, 57(7), 1536-1552. https:// doi.org/10.1177/0042098018821304

Praharaj, S., Han, J. H., \& Hawken, S. (2018). City, culture and society urban innovation through policy integration: Critical perspectives from 100 smart cities mission in India. City, Culture and Society, 12, 35-43. https://doi.org/10. 1016/j.ccs.2017.06.004

Prasad, D., \& Alizadeh, T. (2020). What makes Indian cities smart? A policy analysis of smart cities mission. Telematics and Informatics, 55(January), 101466. https://doi.org/ 10.1016/j.tele.2020.101466

Reshmi, T. R. (2021). Information security breaches due to ransomware attacks - a systematic literature review. International Journal of Information Management Data Insights, 1(2), 100013. https://doi.org/10.1016/j.jjimei. 2021.100013

Ruddin, L. P. (2006). You can generalize stupid! social scientists, bent flyvbjerg, and case study methodology. Qualitative Inquiry, 12(4), 797-812.

Satpathy, S. (2021). Neoliberal regime of land grabbing: A study of bhubaneswar. Nagarlok, LIII Part (January-March), 38-58.

Schlüter, A., Assche, K. V., Hornidge, A., \& Vaidianu, N. (2020). Land-sea interactions and coastal development: An evolutionary governance perspective. Marine Policy. https://doi.org/10.1016/j.marpol.2019.103801

Sharp, L. I. Z., \& Richardson, T. I. M. (2001). Reflections on foucauldian discourse analysis in planning and environmental policy research. Journal of Environmental Policy and Planning, 209, 193-209.

Söderström, O., Paasche, T., \& Klauser, F. (2014). Smart cities as corporate storytelling. City, 18(3), 307-320. https://doi. org/10.1080/13604813.2014.906716

Vaz, A. L. A., Ferreira, F. A. F., Pereira, L. F., Correia, R. J. C., \& Banaitis, A. (2021). Strategic visualization: The (real) usefulness of cognitive mapping in smart city conceptualization. Management Decision. https://doi.org/10.1108/ MD-11-2020-1512

de Vries, J., \& Aalvanger, A. (2015). Negotiating differences: The role of social identity in the emergence of institutions for local governance. In R. Beunen, K. Van Assche, \& M. Duineveld (Eds.), Evolutionary governance theory: Theory and applications. Springer.

Watson, V. (2015). The allure of 'smart city' rhetoric: India and Africa. Dialogues in Human Geography, 5(1), 36-39. https://doi.org/10.1177/2043820614565868

Yin, R. K. (2009). Case study research and applications: Design and methods (5th ed.).

Yin, R. K. (2012). Applications of case study research. Sage Publications, Inc.

Publisher's Note Springer Nature remains neutral with regard to jurisdictional claims in published maps and institutional affiliations. 